\title{
Criptógamos do Parque Estadual das Fontes do Ipiranga, São Paulo, SP, Brasil. Pteridophyta: 1. Aspleniaceae
}

\author{
Regina Yoshie Hirai ${ }^{1,2}$ e Jefferson Prado ${ }^{1}$
}

Recebido: 4.11.2011; aceito: 2.03.2012

\begin{abstract}
Cryptogams of "Parque Estadual das Fontes do Ipiranga", São Paulo, São Paulo State, Brazil. Pteridophyta: 1. Aspleniaceae). The present paper is part of the floristic survey of the "Parque Estadual das Fontes do Ipiranga" carried out by the "Instituto de Botânica". The family Aspleniaceae is native in the area and its represented by one genus and eight species: Asplenium auritum Sw., A. harpeodes Kunze, A. jucundum Fée, A. kunzeanum Klotzsch ex Rosenst., A. mucronatum C. Presl, A. oligophyllum Kaulf., A. raddianum Gaudich., and A. scandicinum Kaulf. Identification keys for species, as well as descriptions, comments, and illustrations are presented.
\end{abstract}

Key words: Asplenium, Atlantic forest, ferns, floristic survey

RESUMO - (Criptógamos do Parque Estadual das Fontes do Ipiranga, São Paulo, SP, Brasil. Pteridophyta: 1. Aspleniaceae). O presente trabalho é parte do levantamento florístico do Parque Estadual das Fontes do Ipiranga, que vem sendo desenvolvido pelo Instituto de Botânica. A família Aspleniaceae é nativa na área e está representada por um único gênero e oito espécies: Asplenium auritum Sw., A. harpeodes Kunze, A. jucundum Fée, A. kunzeanum Klotzsch ex Rosenst., A. mucronatum C. Presl, A. oligophyllum Kaulf., A. raddianum Gaudich. e A. scandicinum Kaulf. São apresentadas chaves para identificação das espécies, bem como descrições, comentários e ilustrações.

Palavras-chave: Asplenium, Floresta Atlântica, levantamento florístico, samambaias

\section{Introdução}

O presente estudo é parte do levantamento florístico das samambaias e licófitas do Parque Estadual das Fontes do Ipiranga (PEFI), que foi iniciado por Hoehne et al. (1941). Até o momento foram publicados os tratamentos para 18 das 24 famílias encontradas na área do Parque (Prado 2004a, b, c, d, e, f, g, 2006a, b, Prado \& Hirai 2008, 2010a, b e Prado et al. 2010).

Recentemente foi publicado o checklist da família Aspleniaceae, dentro do Catálogo de Plantas e Fungos do Brasil, contendo 77 espécies, das quais 22 são endêmicas (Sylvestre 2010a). Anteriormente a essa lista, os trabalhos mais recentes eram pontuais e sobre espécies novas, tais como: Asplenium badinii Sylvestre \& P.G. Windisch, para Minas Gerais (Sylvestre \& Windisch 2008) e Asplenium truncorum F.B. Matos et al., para os Estados da Bahia e Espírito Santo (Matos et al. 2009).
Além desses trabalhos, há um outro que apresenta notas taxonômicas em Aspleniaceae ocorrentes no Brasil, no qual contempla algumas espécies que também ocorrem no Estado de São Paulo, tais como: Asplenium austrobrasiliense (Christ) Maxon, A. bradei Rosenst., A. campos-portoi Brade, A. flabellulatum Kunze, A. gastonis Fée e A. ulbrichtii Rosenst. (Sylvestre 2010b), porém essas espécies não ocorrem na área do PEFI.

Para o Estado de São Paulo especificamente há alguns trabalhos florísticos para determinadas áreas e envolvendo as samambaias e licófitas como um todo, que incluem Aspleniaceae, entre estes: Boldrin \& Prado (2007), para a região do Guarujá, Nóbrega \& Prado (2008), para a região de Bauru e checklists, tais como: Salino (1996), para a Serra do Cuscuzeiro, Salino \& Almeida (2008), para o Parque Estadual de Jacupiranga no Vale do Ribeira, Prado (2004h), para a Serra da Juréia, Prado \& Labiak (2009), para a Reserva Biológica de Paranapiacaba, entre outros.

1. Instituto de Botânica, Núcleo de Pesquisa Curadoria do Herbário, Caixa Postal 68041, 04045-972 São Paulo, SP, Brasil

2. Autor para correspondência: regina.hirai@gmail.com 
O objetivo principal do presente trabalho é a complementação e atualização do levantamento da família Aspleniaceae do PEFI, iniciado por Hoehne et al. (1941), que citou a ocorrência de apenas Asplenium mucronatum C. Presl.

\section{Material e métodos}

O material foi coletado de acordo com as técnicas descritas em Fidalgo \& Bononi (1984) e encontra-se depositado no Herbário do Instituto de Botânica (SP) e no Herbário do Departamento de Botânica da Universidade de São Paulo (SPF).

Os dados sobre a caracterização e localização do Parque Estadual das Fontes do Ipiranga (PEFI), bem como o planejamento desta flora, foram apresentados em Melhem et al. (1981) e Milanez et al. (1990).

$\mathrm{O}$ número que antecede o nome da família, no título deste trabalho, corresponde à numeração das famílias apresentadas em Prado (2004a). A chave para as famílias, incluindo Aspleniaceae, também foi publicada por Prado (2004a).

A abreviação dos nomes dos autores de táxons está de acordo com Pichi-Sermolli (1996).

\section{Resultados e Discussão}

\section{Aspleniaceae}

Plantas terrestres, rupícolas ou epífitas. Caule ereto a reptante, com escamas clatradas. Frondes monomorfas, raramente dimorfas; pecíolo com 2 feixes vasculares na base, nervuras livres ou anastomosadas. Soros lunulares a lineares, ou raramente dentro de uma bolsa quase marginal; ânulo vertical, interrompido pelo pedicelo, pedicelo do esporângio delgado, com uma única fileira de células; esporos aclorofilados, monoletes.
Segundo Smith et al. (2006, 2008), a família apresenta de 1-10 gêneros. A delimitação dos gêneros em Aspleniaceae ainda é incerta e necessita de mais estudos filogenéticos. Por exemplo, diversas propostas de classificação foram feitas para família: Tryon \& Tryon (1982) reconheceram sete gêneros; Kramer \& Green (1990), um único gênero (Asplenium L.) e, posteriormente, no trabalho de Moran (1995), oito gêneros.

Mais recentemente, são reconhecidos dois gêneros na família Aspleniaceae (Asplenium e Hymenasplenium Hayata). Na área do PEFI, ocorre apenas o gênero Asplenium que pode ser facilmente reconhecido pelas características apresentadas na circunscrição a seguir.

\section{Asplenium L.}

Plantas com caule curto-reptante, subereto ou ereto, raramente longo-reptante, com escamas lanceoladas a lineares. Frondes estoloníferas ou não, eretas ou pendentes; pecíolo curto ou longo, às vezes alado, com escamas, raramente com tricomas; lâmina simples ou 1-3-pinada, membranácea a subcoriácea, linear a oval ou subdeltóide, a maioria glabra, poucas espécies com tricomas diminutos; raque glabra, com tricomas septados ou escamas, alada ou não, com ou sem gema prolífera na porção distal. Soros na superfície abaxial da lâmina, sobre o lado acroscópico das nervuras ou, em poucas espécies, também sobre o lado basiscópico (soros diplazióides), oblongos a lineares, ocasionalmente confluentes na maturidade; indúsio linear persistente, inteiro a erodido, frequentemente estreito, delicado e hialino.

Asplenium é um gênero cosmopolita, ocorrendo predominantemente nos trópicos, que apresenta ca. de 700 espécies (Smith et al. 2006).

Chave para as espécies de Aspleniaceae

1. Raque com gema prolífera na porção distal A. kunzeanum

1. Raque sem gema prolífera na porção distal

2. Lâmina 3-4-pinada A. scandicinum

2. Lâmina pinatissecto-pinatífida a 2-pinada

3. Base da pina com lado acroscópico e basiscópico auriculado; ápice das pinas e segmentos mucronados A. mucronatum

3. Base da pina (ou segmento) não auriculado ou se auriculado apenas no lado acroscópico; ápice das pinas ou segmentos agudos ou acuminados

4. Pecíolo cilíndrico

5. Pecíolo alado; pinas elíptico-lanceoladas, ápice agudo A. harpeodes

5. Pecíolo não alado; pinas linear-lanceoladas, ápice acuminado A.jucundum 
4. Pecíolo sulcado adaxialmente

6. Pinas elípticas a lanceoladas; pina apical conforme

A. oligophyllum

6. Pinas trapeziformes ou deltóide-lanceoladas; pina apical pinatífida

7. Pinas (ou segmentos) deltóide-lanceoladas; com uma aurícula ou pínula acroscópica; ápice das pinas (ou segmentos) acuminado a atenuado . A. auritum

7. Pinas trapeziformes; sem aurícula acroscópica; ápice das pinas agudo A. raddianum

Asplenium auritum Sw., J. Bot. (Schrader) 1800(2): 52.1801.

Figuras 1A-D

Plantas epífitas. Caule ereto, com escamas 1,5-6,0 $\times 0,2-1,5 \mathrm{~mm}$, lanceoladas, castanho-escuras, brilhantes, margens inteiras, às vezes com pequenas projeções laterais, ápice agudo. Frondes monomorfas, eretas, 28,0-56,0 × 4,3-15,0 cm; pecíolo sulcado adaxialmente, castanho-claro a castanho-escuro, não alado a estreitamente alado, revestido esparsamente por escamas lineares; lâmina 1-2-pinada, cartácea, oblongo-lanceolada ou deltóide-lanceolada, base levemente obtusa a truncada, ápice acuminado; raque sulcada adaxialmente, não alada a estreitamente alada em toda sua extensão, com algumas escamas lineares abaxialmente; pinas 1,0-7,5 × 1,4-2,8 cm, deltóide-lanceoladas, com algumas escamas lineares na base abaxialmente, base assimétrica, lado acroscópico com uma aurícula ou pínula elíptica a oboval, com margens serreadas a denteadas, às vezes levemente crenadas, ápice acuminado a atenuado; pina apical pinatífida; nervuras livres, simples ou furcadas. Soros elípticos a lineares, próximos à costa; indúsio membranáceo a cartáceo, hialino, margem inteira.

Material examinado: 24-VII-1954, O. Handro 390 (SP); trilha à direita da portaria 2 , bifurcação em direção à Seção de Ecologia, 6-X-2003, J. Prado \& D.M. Vital 1443 (SP, SPF); trilha que margeia o Zoológico, 20-XII-2005, J. Prado \& G.B. Silva 1619 (SP).

Distribuição geográfica: África, Madagascar, México, Guatemala, Belize, Honduras, Nicarágua, Costa Rica, Panamá, Jamaica, Trinidad, Colômbia, Venezuela, Guiana, Suriname, Equador, Peru, Bolívia, Argentina, Paraguai e Brasil - Roraima, Amapá, Pará, Amazonas, Acre, Rondônia, Ceará, Pernambuco, Bahia, Alagoas, Mato Grosso, Goiás, Distrito Federal, Mato Grosso do Sul, Minas Gerais, Espírito Santo, Rio de Janeiro, São Paulo, Paraná, Santa Catarina e Rio Grande do Sul.

Asplenium auritum se assemelha a $A$. gastonis Fée, espécie que não está presente na área do PEFI.
Segundo Sylvestre (2010b), Asplenium auritum difere de A. gastonis por apresentar hábito ereto, lâmina coriácea, pelas nervuras imersas e por apresentar lâmina pinada a pinado-pinatífida, sem no entanto apresentar os caracteres de $A$. gastonis.

Asplenium auritum pode ser reconhecida pela lâmina 1-pinada (figura 1B) ou 2-pinada na base (figura 1D), hábito ereto (figuras $1 \mathrm{~A}, \mathrm{C}$ ) e lâmina cartácea.

Asplenium harpeodes Kunze, Linnaea 18: 329. 1844. Figuras 1E, F

Plantas epífitas. Caule ereto, com escamas 2,5-5,5 × 0,4-0,9 mm, linear-lanceoladas a lineares, castanho-escuras, brilhantes, margens inteiras, ápice filiforme. Frondes monomorfas, pendentes ou eretas, 25,0-48,5 × 2,2-6,2 cm; pecíolo cilíndrico, castanho-escuro a negro, estreitamente alado, às vezes apenas na região distal, revestido na base por escamas lineares; lâmina pinatissecto-pinatífida a 1-pinada, membranácea, lanceolada, base levemente reduzida, pinas proximais um pouco menores do que as medianas, último par de pinas geralmente reflexo, ápice agudo a acuminado; raque cilíndrica, estreitamente alada em toda sua extensão; pinas 1,3-3,5 × 0,5-0,9 cm, elíptico-lanceoladas, base assimétrica, lado acroscópico truncado, lado basiscópico cuneado, margens serreadas, às vezes crenadas, ápice agudo; pina apical pinatífida; nervuras livres, simples, as basais furcadas. Soros elípticos, próximos à costa; indúsio membranáceo, hialino, margem inteira.

Material examinado: 24-XI-1955, O. Handro 556 (SP); 8-III-1974, O. Handro 2248 (SPF); 9-IV-1974, J.A. Corrêa 7 (SP); 16-IV-1974, J.A. Corrêa 26 (SP); 9-IV-1976, J.A. Corrêa 127 (SP).

Distribuição geográfica: México, Guatemala, Honduras, El Salvador, Costa Rica, Nicarágua, Panamá, Jamaica, Haiti, República Dominicana, Venezuela, Colômbia, Guiana, Guiana Francesa, Equador, Peru, Bolívia e Brasil - Minas Gerais, Espírito Santo, Rio de Janeiro, São Paulo, Paraná, Santa Catarina e Rio Grande do Sul. 


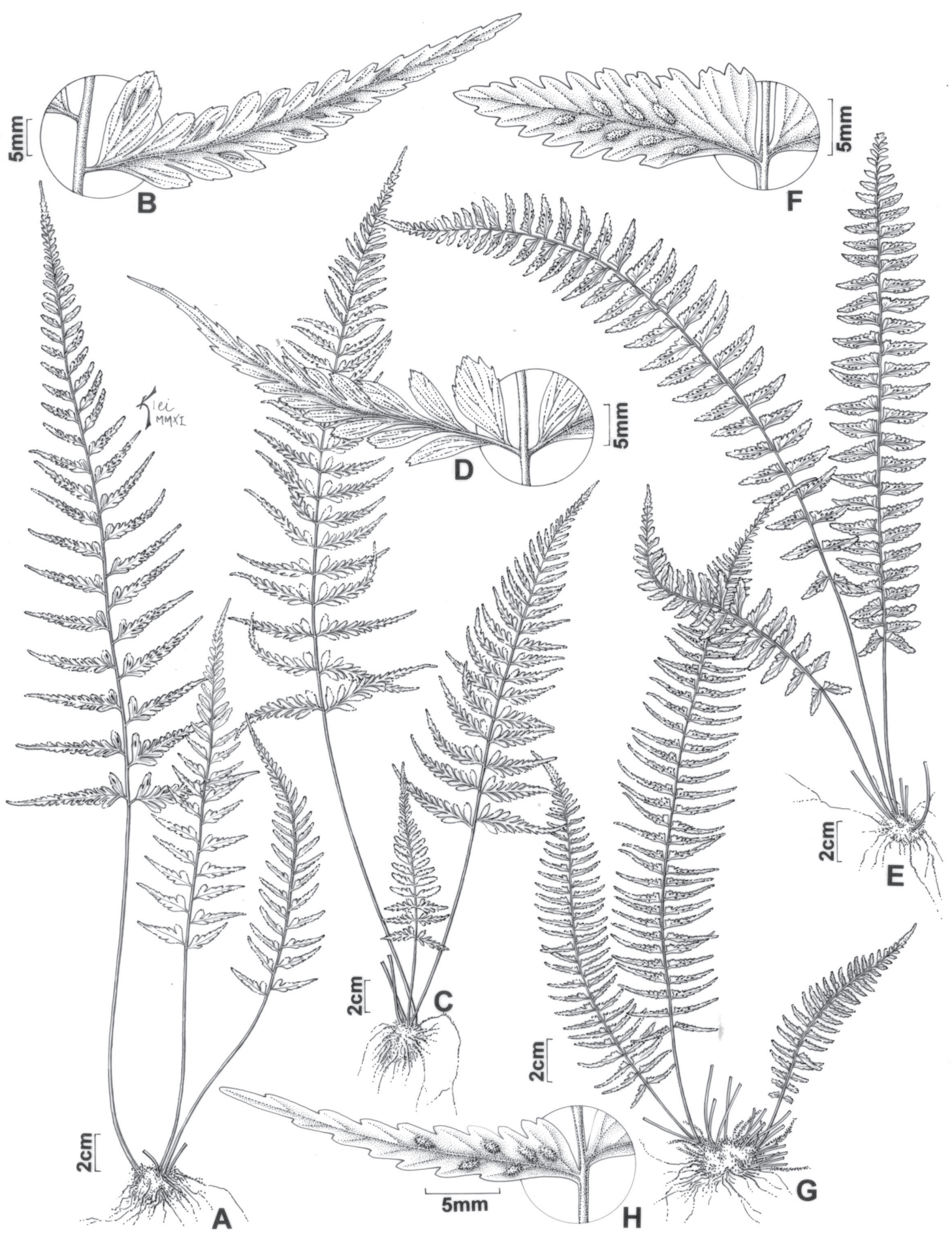

Figura 1. A-D. Asplenium auritum (A-B, Handro 390; C-D, Prado \& Silva 1619). A. Hábito. B. Detalhe da pina fértil com aurícula acroscópica. C. Hábito. D. Detalhe da pina proximal. E-F. A. harpeodes (Corrêa 127). E. Hábito, com frondes mostrando o par de pinas proximais reflexo. F. Detalhe de uma pina fértil. G-H. A. jucundum (Handro 266). G. Hábito, com frondes mostrando o par de pinas proximais patentes. H. Detalhe de uma pina fértil.

Figure 1. A-D. Asplenium auritum (A-B, Handro 390; C-D, Prado \& Silva 1619). A. Habit. B. Detail of the fertile pinna with an acroscopic auricle. C. Habit. D. Detail of the proximal pinna. E-F. A. harpeodes (Corrêa 127). E. Habit with fronds showing the reflexed proximal pinna pair. F. Detail of fertile pinna. G-H. A. jucundum (Handro 266). G. Habit with fronds showing the patent proximal pinna pair. H. Detail of fertile pinna. 
Asplenium harpeodes foi coletada na área do PEFI sobre caules de Alsophila setosa Kaulf., no interior da mata em locais úmidos. Esta espécie pode ser confundida com Asplenium jucundum, que difere principalmente por apresentar pinas linear-lanceoladas, ápice acuminado, além de não apresentar pecíolo alado (vs. elíptico-lanceoladas, ápice agudo e pecíolo alado). Além disso, o último par de pinas de Asplenium jucundum é patente (vs. geralmente reflexo).

Asplenium jucundum Fée, Crypt. Vasc. Brésil 1: 68. tab. 17, fig. 1. 1869.

Figuras $1 \mathrm{G}, \mathrm{H}$

Plantas epífitas. Caule ereto, com escamas 3,5-5,0 $\times$ 0,2-1,0 $\mathrm{mm}$, linear-lanceoladas, castanho-escuras, brilhantes, margens inteiras, raramente com pequenas projeções laterais, ápice filiforme. Frondes monomorfas, eretas, 15,5-30,0 × 2,0-5,0 cm; pecíolo cilíndrico, castanho-escuro a negro, revestido na base por escamas lineares; lâmina 1-pinada, membranácea, lanceolada, base levemente reduzida, último par de pinas proximais um pouco menores do que o penúltimo, patente, ápice acuminado a atenuado; raque cilíndrica, estreitamente alada em quase toda sua extensão; pinas $0,7-2,9 \times 0,3-0,6 \mathrm{~cm}$, linear-lanceoladas, base assimétrica, lado acroscópico obtuso a truncado, lado basiscópico cuneado, margens serreadas, ápice acuminado; pina apical pinatífida; nervuras livres, simples, às vezes as basais do lado acroscópico das pinas furcadas. Soros elípticos, próximos à costa; indúsio membranáceo, hialino, margem inteira.

Material examinado: 12-IX-1951, O. Handro 266 (SP).

Distribuição geográfica: Bolívia e Brasil - Minas Gerais, Espírito Santo, Rio de Janeiro, São Paulo e Paraná.

A espécie mais semelhante é Asplenium harpeodes, mas difere pelas características utilizadas na chave, bem como pelos comentários que estão nesta espécie.

Asplenium kunzeanum Klotzsch ex Rosenst., Hedwigia 46: 100. 1906.

Figuras 2A, B

Plantas terrestres. Caule ereto, com escamas 2,5-3,5 × 0,4-0,5 mm, lanceoladas a linear-lanceoladas, castanhas a negras, brilhantes, margens inteiras, ápice acuminado a atenuado. Frondes monomorfas, eretas, 57,0-66,5 × 4,7-11,2 cm; pecíolo sulcado adaxialmente, castanho-escuro a negro, alado, revestido na base por escamas lanceoladas, às vezes as medianas lineares; lâmina 1-pinada, membranácea, lanceolada, base levemente reduzida; pinas proximais geralmente um pouco menores, ápice agudo; raque sulcada adaxialmente, estreitamente alada em toda sua extensão, com gema prolífera na porção distal; pinas 3,4-6,6 × 1,1-1,7 cm, oblongas, base assimétrica, lado acroscópico truncado, lado basiscópico cuneado, margens serreadas, ápice agudo a arredondado; pina apical pinatífida; nervuras livres, furcadas, as apicais simples. Soros elípticos a lineares, próximos à costa; indúsio membranáceo, hialino, margem inteira a levemente ondulada.

Material examinado: 25-X-1951, O. Handro 272 (SP); 10-V-1973, O. Handro 2223 (SPF).

Distribuição geográfica: Endêmica do Brasil - Bahia, Minas Gerais, Espírito Santo, Rio de Janeiro, São Paulo, Paraná, Santa Catarina e Rio Grande do Sul.

$\mathrm{Na}$ área do PEFI esta espécie é facilmente reconhecida por apresentar gemas prolíferas na porção distal da raque. É a única espécie que ocorre na área do Parque que apresenta estas gemas.

Asplenium mucronatum C. Pres1, Delic. Prag. 1. 178. 1822.

Figuras 2C, D

Plantas epífitas. Caule ereto, com escamas 1,1-1,7 × 0,2-0,6 mm, lanceoladas a linear-lanceoladas, castanho-escuras a negras, brilhantes, margens inteiras, ápice agudo a atenuado. Frondes monomorfas, pendentes, 15,5-64,0 × 2,0-6,3 cm; pecíolo cilíndrico, castanho-escuro a negro, glabro; lâmina pinado-pinatífida, membranácea, longamente linear-lanceolada, base gradualmente reduzida, pinas proximais menores do que as medianas, ápice agudo a acuminado; raque alada, ala estreita; pinas 1,6-4,1 $\times 0,6-1,0 \mathrm{~cm}$, ovais a oblongas, base simétrica, lado acroscópico e basiscópico auriculado, aurícula bífida ou trífida, ápice das pinas e dos segmentos mucronado; pina apical pinatífida; nervuras livres, simples, exceto as da aurícula que são furcadas. Soros elípticos; indúsio membranáceo, hialino, margem ondulada.

Material examinado: 4-VII-1939, O. Handro s.n.

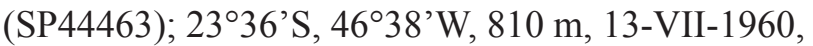
G. Eiten et al. 2059, 2077 (SP); 2-IV-1974, J.A. Corrêa 3 (SP); 9-IV-1974, J.A. Corrêa 10 
(SP); 9-IV-1976, J.A. Corrêa 128 (SP); 2-VI-1976, J.A. Corrêa 135 (SP); na trilha atrás do novo prédio do Herbário, 5-II-2004, J. Prado 1457 (SP, SPF).

Distribuição geográfica: Argentina, Paraguai e Brasil - Minas Gerais, Rio de Janeiro, São Paulo, Paraná, Santa Catarina e Rio Grande do Sul.

$\mathrm{Na}$ área do PEFI Asplenium mucronatum foi encontrada crescendo sobre caule de Cyatheaceae. Esta espécie é facilmente reconhecida pelas frondes pendentes, pinas ovais a oblongas, com ápice mucronado.

Asplenium oligophyllum Kaulf., Enum. Filic. 166. 1824.

Figuras 2E, F

Plantas epífitas. Caule ereto, com escamas 5,0-7,5 × 1,5-2,0 mm, lanceoladas, castanho-escuras, brilhantes, margens levemente laceradas, às vezes com pequenas projeções laterais, ápice acuminado. Frondes monomorfas, eretas, 27,0-57,0 $\times 6,0-23,5 \mathrm{~cm}$; pecíolo sulcado adaxialmente, castanho a castanho-escuro, com escamas lanceoladas na base; lâmina 1-pinada, cartácea, oval, base cuneada, margens levemente serreadas a crenadas, ápice agudo; raque sulcada adaxialmente, estreitamente alada, principalmente próxima a base das pinas, com escamas esparsas lanceoladas a lineares abaxialmente; pinas $7,2-15,0 \times 1,1-2,6 \mathrm{~cm}$, elípticas a lanceoladas, base cuneada, margens serreadas a crenadas, ápice agudo; pina apical conforme, 19-21 × 2,8-3,0 cm; nervuras livres, geralmente furcadas, simples no ápice. Soros lineares, próximos à costa; indúsio membranáceo, hialino, margem inteira.

Material examinado: 3-VII-1950, O. Handro 182 (SP); 9-IV-1974, J.A. Corrêa 6 (SP).

Distribuição geográfica: Venezuela, Bolívia, Argentina, Paraguai e Brasil - Bahia, Minas Gerais, Espírito Santo, Rio de Janeiro, São Paulo, Paraná, Santa Catarina e Rio Grande do Sul.

Esta espécie se caracteriza por apresentar pinas elípticas a lanceoladas e, principalmente, por ser a única espécie da área do Parque que apresenta uma pina apical conforme, i.e., igual às pinas laterais.

Asplenium raddianum Gaudich., Voy. Uranie, Bot. 316. 1828.

Figuras $2 \mathrm{G}, \mathrm{H}$

Plantas epífitas. Caule ereto, com escamas 3,0-5,0 $\times 0,3-0,9 \mathrm{~mm}$, lanceoladas, castanho-escuras, brilhantes, margens inteiras, ápice agudo a acuminado. Frondes monomorfas, eretas, 20,5-27,0 × 2,5-3,8 cm; pecíolo sulcado adaxialmente, castanho a castanho-escuro, estreitamente alado, revestido esparsamente por escamas lineares; lâmina 1-pinada, membranácea, lanceolada, base levemente reduzida, pinas proximais menores do que as medianas, ápice agudo a acuminado; raque sulcada adaxialmente, estreitamente alada em toda sua extensão; pinas 0,9-1,9 $\times 0,5-1,0 \mathrm{~cm}$, trapeziformes, base assimétrica, lado acroscópico truncado, lado basiscópico cuneado, margens serreadas, ápice agudo; pina apical pinatífida; nervuras livres, simples, as basais do lado acroscópico das pinas furcadas. Soros elípticos, próximos à costa; indúsio membranáceo, hialino, margem inteira.

Material examinado: 8-II-1949, O Handro 84 (SP).

Distribuição geográfica: Peru, Bolívia e Brasil - Minas Gerais, Espírito Santo, Rio de Janeiro, São Paulo, Paraná, Santa Catarina e Rio Grande do Sul.

A espécie mais semelhante à Asplenium raddianum na área do PEFI é $A$. harpeodes. Esta última espécie pode ser reconhecida pelo pecíolo e raque cilíndricos (vs. pecíolo e raque sulcados adaxialmente).

Asplenium scandicinum Kaulf., Enum. Filic. 177. 1824.

Figuras 2I, J

Plantas epífitas. Caule ereto, com escamas 5,0-6,5 × 0,5-0,9 mm, linear-lanceoladas, castanho-negras, brilhantes, margens inteiras, ápice filiforme. Frondes monomorfas, pendentes, 45,0-50,0 × 23,5-30,0 cm; pecíolo levemente sulcado adaxialmente, amarelado a castanho-claro, raramente com escamas lineares na base; lâmina 3-4-pinada, cartácea, deltóide, base truncada, ápice acuminado a caudado; raque levemente sulcada adaxialmente, não alada; pinas proximais, 13,0-16,0 × 8,5-13,0 cm, deltóides, base truncada, ápice acuminado a atenuado, segmentos levemente flabeliformes, serreados, agudos; nervuras livres, simples e furcadas; pina apical levemente pinatífida. Soros elíptico-lineares, próximos à costa; indúsio membranáceo, hialino, margem inteira a levemente ondulada.

Material examinado: 9-IV-1976, J.A. Corrêa 131 (SP).

Distribuição geográfica: Argentina e Brasil - Bahia, Minas Gerais, Espírito Santo, Rio de Janeiro, São Paulo, Paraná, Santa Catarina e Rio Grande do Sul.

$\mathrm{Na}$ área do PEFI, esta é a única espécie de Asplenium que apresenta a lâmina 3-4-pinada e por isso é facilmente reconhecida. 


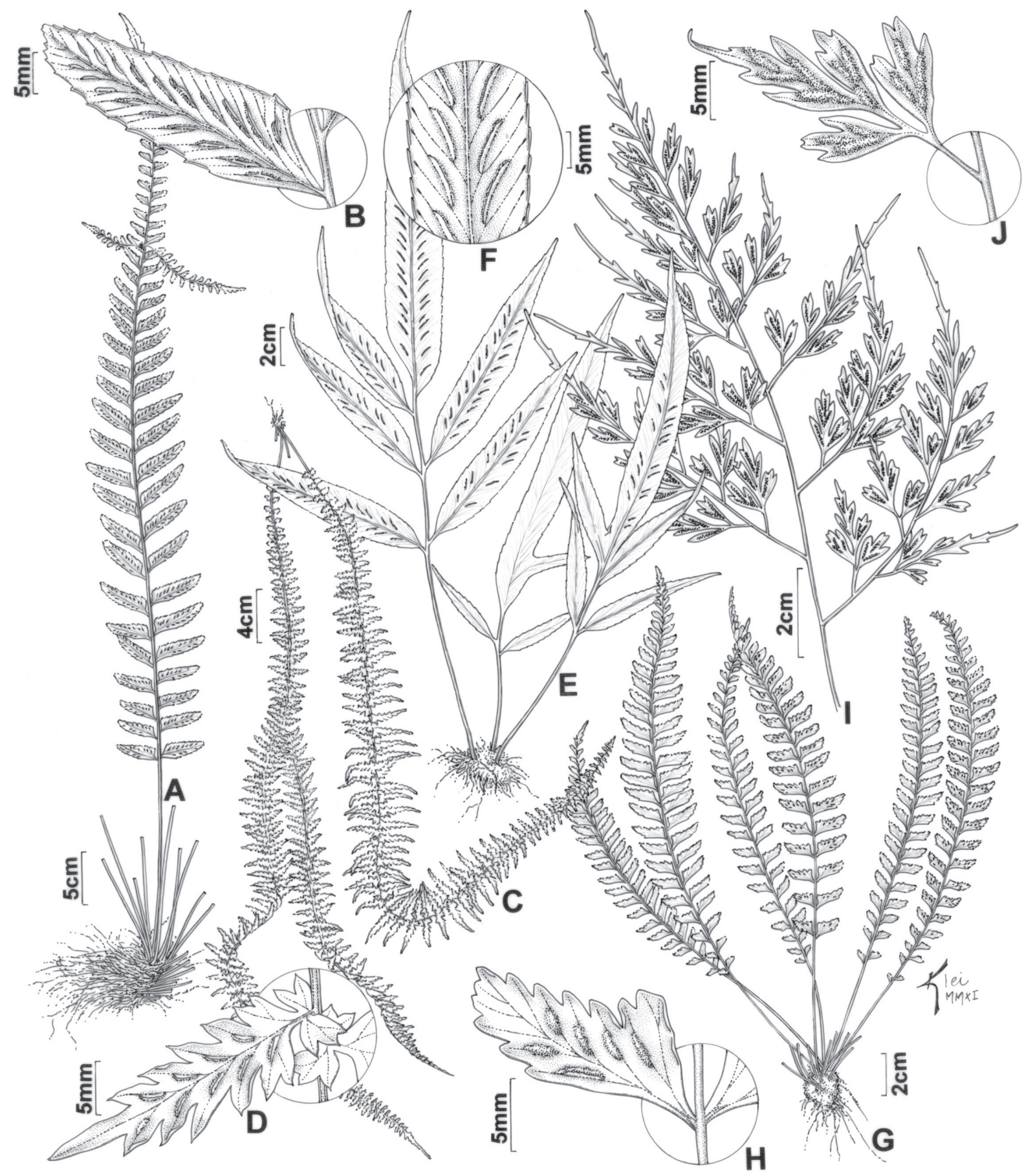

Figura 2. A-B. Asplenium kunzeanum (Handro 272). A. Hábito, mostrando uma fronde com gema prolífera. B. Detalhe de uma pina fértil. C-D. A. mucronatum (Prado 1457). C. Hábito pendente. D. Detalhe do segmento fértil biauriculado, com aurícula bífida acroscopicamente e trífida basiscopicamente. E-F. A. oligophyllum (Corrêa 6). E. Hábito. F. Detalhe dos soros. G-H. A. raddianum (Handro 84). G. Hábito. H. Detalhe da pina fértil. I-J. A. scandicinum (Corrêa 131). I. Parte de uma fronde fértil. J. Detalhe do segmento fértil.

Figure 2. A-B. Asplenium kunzeanum (Handro 272). A. Habit showing a frond with proliferous gema. B. Detail of fertile pinna. C-D. A. mucronatum (Prado 1457). C. Pendent habit. D. Detail of biauriculate fertile segment, with bifid auricle acroscopically and trifid auricle basiscopically. E-F. A. oligophyllum (Corrêa Ø). E. Habit. F. Detail of the sori. G-H. A. raddianum (Handro 84). G. Habit. H. Detail of fertile pinna. I-J. A. scandicinum (Corrêa 131). I. Part of the fertile frond. J. Detail of fertile segment. 
Algumas espécies epífitas, tais como Asplenium jucundum, A. raddianum e $A$. scandicinum não foram recentemente encontradas na área do PEFI, apesar do esforço de coleta para localizá-las. De modo geral, as espécies epífitas de samambaias e licófitas são menos frequentes no Parque do que as espécies terrestres. Provavelmente este fato é em decorrência da poluição atmosférica, que impede o desenvolvimento das plantas epífitas.

\section{Agradecimentos}

Ao CNPq pela concessão da Bolsa de Produtividade em Pesquisa (do segundo autor) e auxílio para este projeto (processo 300843-93-3). O segundo autor também agradece ao Daniel M. Vital pela ajuda no trabalho de campo.

\section{Literatura citada}

Boldrin, A.H.L. \& Prado, J. 2007. Pteridófitas terrestres e rupícolas do Forte dos Andradas, Guarujá, São Paulo, Brasil. Boletim de Botânica da Universidade de São Paulo 25: 1-69.

Fidalgo, O. \& Bononi, V.L.R. 1984. Técnicas de coleta, preservação e herborização de material botânico. Manual 4. Instituto de Botânica, São Paulo.

Hoehne, F.C., Kuhlmann, M. \& Handro, O. 1941. O Jardim Botânico de São Paulo. Secretaria da Agricultura, Indústria e Comércio, Departamento de Botânica do Estado, São Paulo.

Kramer, K.U. \& Green, P.S. 1990. The families and genera of vascular plants, v. 1, Pteridophytes and Gymnosperms. Springer-Verlag, Berlin.

Matos, F.B., Labiak, P.H. \& Sylvestre, L.S. 2009. A new Brazilian species of the genus Asplenium L. (Aspleniaceae). American Fern Journal 99: 101-105.

Melhem, T.S., Giulietti, A.M., Forero, E., Barroso, G.M., Silvestre, M.S.F., Jung, S.L., Makino, H., Melo, M.M.R.F., Chiea, S.C., Wanderley, M.G.L., Kirizawa, M. \& Muniz, C. 1981. Planejamento para elaboração da "Flora Fanerogâmica da Reserva do Parque Estadual das Fontes do Ipiranga (São Paulo, Brasil)". Hoehnea 9: 63-74.

Milanez, A.I., Bicudo, C.E.M., Vital, D.M. \& Grandi, R.A.P. 1990. Criptógamos do Parque Estadual das Fontes do Ipiranga, São Paulo, SP: Planejamento. Hoehnea 17: 43-49.

Moran, R.C. 1995. Aspleniaceae. In: R.C. Moran \& R. Riba (eds.). Psilotaceae a Salviniaceae. In: G. Davidse, M.S. Sousa \& S. Knapp (eds.). Flora Mesoamericana, v. 1. Universidade Nacional Autónoma de México, Ciudad de México, pp. 290-325.
Nóbrega, G.A. \& Prado, J. 2008. Pteridófitas da vegetação nativa do Jardim Botânico Municipal de Bauru, Estado de São Paulo, Brasil. Hoehnea 35: 7-55.

Pichi-Sermolli, R.E.G. 1996. Authors of scientific names in Pteridophyta. Royal Botanic Gardens, Kew.

Prado, J. 2004a. Criptógamos do Parque Estadual das Fontes do Ipiranga, São Paulo, SP. Pteridophyta: chave para as famílias; 2. Blechnaceae. Hoehnea 31: 1-10.

Prado, J. 2004b. Criptógamos do Parque Estadual das Fontes do Ipiranga, São Paulo, SP. Pteridophyta: 6. Dicksoniaceae. Hoehnea 31: 239-242.

Prado, J. 2004c. Criptógamos do Parque Estadual das Fontes do Ipiranga, São Paulo, SP. Pteridophyta: 14. Ophioglossaceae. Hoehnea 31: 171-174.

Prado, J. 2004d. Criptógamos do Parque Estadual das Fontes do Ipiranga, São Paulo, SP. Pteridophyta:17. Pteridaceae. Hoehnea 31: 39-49.

Prado, J. 2004e. Criptógamos do Parque Estadual das Fontes do Ipiranga, São Paulo, SP. Pteridophyta: 8. Gleicheniaceae. Hoehnea 31: 33-37.

Prado, J. 2004f. Criptógamos do Parque Estadual das Fontes do Ipiranga, São Paulo, SP. Pteridophyta: 5. Dennstaedtiaceae. Hoehnea 31: 11-22.

Prado, J. 2004g. Criptógamos do Parque Estadual das Fontes do Ipiranga, São Paulo, SP. Pteridophyta: 15. Osmundaceae. Hoehnea 31: 93-96.

Prado, J. 2004h. Pteridófitas do Maciço da Juréia. In: O.A.V. Marques \& W. Duleba (eds.), Estação Ecológica Juréia-Itatins. Ambiente físico, flora e fauna. Editora Holos, Ribeirão Preto, São Paulo, pp. 139-151.

Prado, J. 2006a. Criptógamos do Parque Estadual das Fontes do Ipiranga, São Paulo, SP. Pteridophyta: 18. Salviniaceae. Hoehnea 33: 107-110.

Prado, J. 2006b. Criptógamos do Parque Estadual das Fontes do Ipiranga, São Paulo, SP. Pteridophyta: 12. Lophosoriaceae. Hoehnea 33: 123-126.

Prado, J. \& Hirai, R.Y. 2008. Criptógamos do Parque Estadual das Fontes do Ipiranga, São Paulo, SP. Pteridophyta: 13. Lycopodiaceae e 20. Selaginellaceae. Hoehnea 35: 543-552.

Prado, J. \& Hirai, R.Y. 2010a. Criptógamos do Parque Estadual das Fontes do Ipiranga, São Paulo, SP. Pteridophyta: 21. Tectariaceae. Hoehnea 37: 367-376.

Prado, J. \& Hirai, R.Y. 2010b. Criptógamos do Parque Estadual das Fontes do Ipiranga, São Paulo, SP. Pteridophyta: 4. Davalliaceae, 19. Schizaeaceae, 23. Vittariaceae e 24. Woodsiaceae. Hoehnea 37: 791-800.

Prado, J., Hirai, R.Y. \& Schwartsburd, P.B. 2010. Criptógamos do Parque Estadual das Fontes do Ipiranga, São Paulo, SP. Pteridophyta: 9. Grammitidaceae e 16. Polypodiaceae. Hoehnea 37: 445-460. 
Prado, J. \& Labiak, P.H. 2009. Pteridófitas. In: M.I.M.S. Lopes, M. Kirizawa \& M.M.R.F. Melo (orgs.). Patrimônio da Reserva Biológica do Alto da Serra de Paranapiacaba: a antiga Estação Biológica do Alto da Serra. Instituto de Botânica, São Paulo, pp. 269-289.

Salino, A. 1996. Levantamento das pteridófitas da Serra do Cuscuzeiro, Analândia, SP, Brasil. Revista Brasileira de Botânica 19: 173-178.

Salino, A. \& Almeida, T.E. 2008. Pteridófitas do Parque Estadual de Jacupiranga, SP, Brasil. Acta Botanica Brasilica 22: 983-991.

Smith, A.R., Pryer, K.M., Schuettpelz, E., Korall, P., Schneider, H. \& Wolf, P.G. 2006. A classification for extant ferns. Taxon 55: 705-731.

Smith, A.R., Pryer, K.M., Schuettpelz, E., Korall, P., Schneider, H. \& Wolf, P.G. 2008. Fern classification. In: T.A. Ranker \& C.H. Haufler (eds.). Biology and evolution of ferns and lycophytes. Cambridge University Press, Cambridge, pp. 417-467.
Sylvestre, L.S. 2010a. Aspleniaceae. In: J. Prado \& L.S. Sylvestre (coords.). Samambaias e licófitas. In: R.C. Forzza, J.F. Baumgratz, C.E. de M. Bicudo, D. Canhos, A.A. Carvalho Jr., A. Costa, D.P. Costa, M. Hopkins, M.P. Leitman, L.G. Lohmann, E.N. Lughadha, L.C. Maia, G. Martinelli, M. Menezes, M.P. Morin, M. Nadruz, A.L. Peixoto, J.R. Pirani, J. Prado, L.P. Queiroz, S. de Souza, V.C. Souza, J.R. Stehmann, L.S. Sylvestre, B.M.T. Walter \& D.C. Zappi (eds.). Catálogo de Plantas e Fungos do Brasil. 1a ed. Jardim Botânico do Rio de Janeiro, Rio de Janeiro, v. 1, pp. 525-527.

Sylvestre, L.S. 2010b. Notas taxonômicas em Aspleniaceae (Polypodiopsida) ocorrentes no Brasil. Rodriguésia 61: 109-114.

Sylvestre, L.S. \& Windisch, P.G. 2008. Asplenium badinii (Aspleniaceae), a new endemic fern species from Minas Gerais, Brazil. Novon 18: 538-541.

Tryon, R.M. \& Tryon, A.F. 1982. Ferns and allied plants, with special reference to tropical America. Springer-Verlag, New York. 